\title{
Acid-induced cell injury and death in lung epithelial cells is associated with the activation of mitogen-activated protein kinases
}

\author{
QIUHUA CHEN, YINGZI HUANG, YI YANG and HAIBO QIU
}

Department of Critical Care Medicine, Nanjing Zhong-Da Hospital, Southeast University School of Medicine, Nanjing, Jiangsu 210009, P.R. China

Received February 4, 2013; Accepted June 11, 2013

DOI: $10.3892 / \mathrm{mmr} .2013 .1537$

\begin{abstract}
Gastric hydrochloric acid $(\mathrm{HCl})$ has been regarded as a causative factor of acute lung injury (ALI). The activation of mitogen-activated protein kinases (MAPKs) has been suggested to be a mechanism involved in the pathogenesis of ALI in vivo. However, the effects of $\mathrm{HCl}$ on MAPK activation in lung epithelial cells remain to be fully elucidated. Further investigation into the role of MAPK activation in acid-induced cell injury and death is also needed. In the present study, BEAS-2B cells were treated with $\mathrm{HCl}$ ( $\mathrm{pH} 4.0$ medium) for 5, 15 and $30 \mathrm{~min}$, and the acidified medium was then removed. Cell viability and death were detected by MTT assay and trypan blue exclusion staining, respectively. The activation of MAPKs [c-Jun N-terminal kinase (JNK), p38 MAPK and extracellular signal-regulated kinase (ERK) 1/2] was analyzed by western blot analysis. Cytotoxicity was assessed by lactate dehydrogenase (LDH) release, and IL-8 levels in culture supernatants were measured by enzyme-linked immunosorbent assay (ELISA). Cell apoptosis was detected as changes in the levels of capase-3, Bad and fas by western blot analysis and the number of apoptotic cells by using Annexin V/propidium iodide (PI) staining. Following pre-treatment with the JNK inhibitor II $(10 \mu \mathrm{mol} / \mathrm{l})$, the $\mathrm{p} 38$ inhibitor SB202190 $(10 \mu \mathrm{mol} / \mathrm{l})$ or the ERK inhibitor U0126 (10 $\mu \mathrm{mol} / \mathrm{l})$ for $30 \mathrm{~min}$, BEAS-2B cells were exposed to $\mathrm{HCl}$ for $30 \mathrm{~min}$. Cell viability, cytotoxicity, IL-8 levels and apoptosis were detected $4 \mathrm{~h}$ following acid stimulation. The viability of BEAS-2B cells was inhibited and cell death was increased in the presence of $\mathrm{HCl} . \mathrm{HCl}$ stimulation induced activation of MAPKs in a time-dependent manner. $\mathrm{HCl}$ exposure increased the levels of IL-8 and the release of $\mathrm{LDH}$, and induced apoptosis in BEAS-2B cells. JNK and p38 inhibitors increased cell viability and decreased
\end{abstract}

Correspondence to: Professor Haibo Qiu, Department of Critical Care Medicine, Nanjing Zhong-Da Hospital, Southeast University School of Medicine, 87 Dingjiaqiao Road, Nanjing, Jiangsu 210009, P.R. China

E-mail: haiboq2000@yahoo.com.cn

Key words: acute lung injury, acute respiratory distress syndrome, hydrochloric acid, mitogen-activated protein kinase, apoptosis cytotoxicity and cell apoptosis, while ERK inhibitor had no effect on cell viability, cytotoxicity or apoptosis. These results indicate that acid exposure induced epithelial cell injury and death. The activation of JNK and p38 is involved in $\mathrm{HCl}$-induced epithelial lung cell injury and death.

\section{Introduction}

Acute respiratory distress syndrome (ARDS) is a multifactorial, heterogeneous disease associated with high rates of mortality and disability in critically ill patients (1-3). Acid aspiration-induced lung injury accounts for $\sim 11 \%$ of all clinical ARDS cases and is a major cause of morbidity in cases of critical illness $(4,5)$. Acid aspiration-induced ARDS is characterized by pulmonary edema from increased vascular and epithelial permeability, as well as alveolar and interstitial inflammation with leukocyte infiltration (6). Cell death has been demonstrated in the lung during the pathogenesis of acute lung injury (ALI)/ARDS. However, the mechanism of acid-induced cell injury and death in ALI has yet to be fully elucidated.

Mitogen-activated protein kinases (MAPKs), including the c-Jun NH2-terminal kinase (JNK), p38 MAPK and extracellular signal-regulated kinase (ERK) 1/2, are commonly involved in the pathogenesis of ALI. JNK and p38 MAPK modules are involved in cell survival and apoptosis, while the ERK module has been shown to play a crucial role in cell proliferation. Lipopolysaccharide (LPS) has been shown to induce the activation of MKK3/p38 signaling pathways and epithelial/endothelial cell apoptosis in animal models of ALI $(7,8)$. However, changes in JNK, p38 and ERK1/2 expression following exposure of lung epithelial cells to acid remain to be fully elucidated. Further investigation is also needed with regard to the effects of MAPK pathway blockade on cell injury and death.

The present study investigated the effects of acid exposure on MAPK pathways, cell injury and death in lung epithelial cells using JNK, p38 and ERK1/2 inhibitors. The main pathways involved in acid-induced epithelial cell injury and death were identified.

\section{Materials and methods}

Materials. All of the reagents were purchased from Sigma-Aldrich (St. Louis, MO, USA), BD Biosciences 
(Bedford, MA, USA) and Corning Costar (Cambridge, MA, USA) unless otherwise specified. JNK inhibitor II, SB202190 (p38 inhibitor) and U0126 (ERK1/2 inhibitor) were purchased from Calbiochem (San Diego, CA, USA). The cell proliferation (MTT) and cytotoxicity detection kits [lactate dehydrogenase cytotoxicity (LDH)] were obtained from Roche $\mathrm{GmbH}$ (Mannheim, Germany). Mouse anti-phospho-JNK, mouse anti-JNK, mouse anti-phospho-p38 MAP kinase, mouse anti-p38 MAP kinase, mouse anti-phospho-ERK1/2, mouse anti-ERK1/2, mouse anti-fas, mouse anti-Bad and mouse anti-GAPDH antibodies were obtained from Santa Cruz Biotechnology,Inc.(SantaCruz,CA,USA).Rabbitanti-capase-3 antibody was purchased from Abcam (Cambridge, UK). Goat anti-mouse, goat anti-rabbit and donkey anti-goat IgGs were purchased from Jackson ImmunoResearch Laboratories, Inc. (West Grove, PA, USA). An electrochemiluminescence (ECL) kit was obtained from Pierce Biotechnology, Inc. (Rockford, IL, USA). Electrophoresis reagents and equipment were purchased from Bio-Rad (Hercules, CA, USA).

BEAS-2B epithelial cell culture. Human lung epithelial BEAS-2B cells [American Type Culture Collection (ATCC), Manassas, VA, USA] were grown as a monolayer in $5 \% \mathrm{CO}_{2}$ at $37^{\circ} \mathrm{C}$ in Dulbecco's modified Eagle's medium (DMEM) supplemented with $10 \%$ heat-inactivated fetal bovine serum (FBS), $50 \mathrm{U} / \mathrm{ml}$ penicillin and $50 \mathrm{mg} / \mathrm{ml}$ streptomycin (complete medium). BEAS-2B cells were seeded in 6-, 12- or 24-well culture plates for each experiment.

Acid exposure. BEAS-2B cells were plated at densities of $4 \times 10^{5}$ cells/well in 6-well plates. After $24 \mathrm{~h}$ of incubation, the medium was changed to serum-free DMEM followed by a $24-\mathrm{h}$ culture. The cells were then treated with $\mathrm{HCl}(\mathrm{pH}$ 4.0 DMEM) for 5,15 and $30 \mathrm{~min}$ at $37^{\circ} \mathrm{C}$ in $5 \% \mathrm{CO}_{2}$. Negative control cells were exposed to phosphate-buffered saline (PBS) at the same volume of $\mathrm{HCl}$ used in the acid-exposed group. After incubation with $\mathrm{HCl}$, the acidified medium was discarded, and the cells were washed three times with complete medium to confirm neutralization of the culture medium (9). BEAS-2B cells were then cultured with serum-free DMEM for an additional $4 \mathrm{~h}$.

Cell pre-treatment with JNK inhibitor II, SB202190 or U0126. In the MAPK inhibitor pre-treatment experiments, BEAS-2B cells were incubated with JNK inhibitor II, SB202190 or $\mathrm{U} 0126$ at $10 \mu \mathrm{M}$ for $30 \mathrm{~min}$ prior to $\mathrm{HCl}$ exposure (10-12). Pre-treatments were initiated by adding concentrated solutions to reach the final concentrations in each well. JNK inhibitor II, SB202190 and U0126 stock solutions were prepared by dissolution in DMSO as the vehicle.

Cell viability measurements using the MTT assay. Cell viability was measured using the MTT reduction assay as previously described (13). BEAS-2B cells (2.5x104/well) were grown in $100 \mu \mathrm{l}$ of DMEM containing 10\% FBS using 96-well plates. Briefly, after exposure to $\mathrm{HCl}$ ( $\mathrm{pH} 4.0 \mathrm{DMEM}$ ) for 5, 15 or $30 \mathrm{~min}$, the supernatant was removed, and the cells were gently washed with complete medium and incubated with $100 \mu \mathrm{l}$ of fresh culture medium and $10 \mu \mathrm{l}$ MTT $(5 \mathrm{mg} / \mathrm{ml})$. After $4 \mathrm{~h}$ of incubation, $100 \mu \mathrm{l}$ of the solubilization solution was added to dissolve the formazan crystals overnight, and the absorbance was read using a microplate reader (SpectraMax M5, Molecular Devices, CA, USA) at a wavelength of $570 \mathrm{~nm}$. Using the control wells to determine optimum cell growth, cell viability was defined as the percentage of the average absorbance of treated wells divided by the absorbance of control wells.

Cell death assessment by trypan blue staining. Cell death was determined after treatment with $\mathrm{HCl}$ using a trypan blue dye exclusion assay, as previously described (14). BEAS-2B cells (4x $10^{5} /$ well) were grown in 6-well plates. Following $\mathrm{HCl}$ exposure, the cells were detached by trypsinization and collected after centrifugation. The cells were resuspended in PBS and incubated with an equal volume of $0.4 \%$ trypan blue for $5 \mathrm{~min}$ at room temperature. The number of dead cells (stained cells) was counted using a hemocytometer and expressed as a percentage of the total cells counted.

Detection of cytotoxicity by the $\mathrm{LDH}$ assay. $\mathrm{LDH}$ is a stable cytoplasmic enzyme present in most cells and is released into cell culture supernatant when the cell membrane is damaged. LDH assays were performed using a non-radioactive alternative to the $\left({ }^{3} \mathrm{H}\right)$-thymidine-release assay and the $\left({ }^{51} \mathrm{Cr}\right)$-release assay (catalogue no. 11644793001). BEAS-2B cells were grown in 6-well plates until confluent, serum starved for $24 \mathrm{~h}$ and exposed to previously defined experimental conditions ( 3 wells each). At $4 \mathrm{~h}$, the medium was collected, centrifuged at $4^{\circ} \mathrm{C}$ for $5 \mathrm{~min}$ and incubated with the appropriate kit reagents. The absorbance was then measured with a spectrophotometer at $490 \mathrm{~nm}$ and compared with the appropriate control cells.

Detection of apoptosis by Annexin V-FITC/propidium iodide (PI) staining. Annexin V-FITC/PI staining was performed to detect apoptotic cells following acid exposure. BEAS-2B cells were plated into 24-well plates and treated with $\mathrm{HCl}$ for $30 \mathrm{~min}$. BEAS-2B cells were then gently washed, and stained with Annexin V-FITC (green fluorescence) and PI (red fluorescence) for $15 \mathrm{~min}$ in the dark at room temperature. The cells were observed using a dual wavelength fluorescence microscope (Nikon, Tokyo, Japan).

Western blot analysis. Total proteins were extracted from BEAS-2B cells in lysis buffer $(0.1 \%$ Triton X-100) and separated by $12 \%$ SDS-PAGE under reducing conditions. The samples were then transferred onto polyvinylidene difluoride (PVDF) membranes. The membranes were blocked

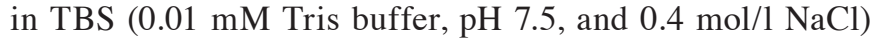
containing $0.1 \%$ Tween-20 and 5\% skimmed milk for $1 \mathrm{~h}$ and incubated with $2 \mu \mathrm{g} / \mathrm{ml}$ mouse anti-human p-JNK, JNK, p-p38, p38, p-ERK, ERK, fas, Bad or capase-3 in a primary antibody dilution buffer at $4^{\circ} \mathrm{C}$ overnight. After washing, the membranes were incubated with horseradish peroxidase (HRP)-conjugated goat anti-mouse, goat anti-rabbit or donkey anti-goat $\operatorname{IgG}$ (dilution, 1:15,000), and the signals were detected using an ECL kit.

IL- 8 assay. IL-8 levels in the supernatants were measured using an enzyme-linked immunosorbent assay (ELISA) kit according to the manufacturer's instructions. 
Statistical analysis. All the data are expressed as the means \pm SD. Statistical analysis was performed using SPSS 16.0 (SPSS, Inc., Chicago, IL, USA). Group comparisons were performed using one-way ANOVA, followed by the Student-Newman-Keuls test for pairwise multiple comparisons. $\mathrm{P}<0.05$ was considered to indicate a statistically significant difference.

\section{Results}

$\mathrm{HCl}$ exposure reduces BEAS-2B cell viability and induces $B E A S-2 B$ cell death. We examined whether exposure to $\mathrm{HCl}$ affects the viability of BEAS-2B cells and induces cell death. As shown in Fig. 1A, the viability of BEAS-2B cells decreased in a time-dependent manner after stimulation with acid. BEAS-2B cell death increased with treatment time following $\mathrm{HCl}$ stimulation $(\mathrm{P}<0.05) ; 19 \%$ cell death was observed when the cells were exposed to $\mathrm{HCl}$ for $30 \mathrm{~min}$ (Fig. 1B).

$\mathrm{HCl}$ exposure activates MAPK family proteins in a time-dependent manner. To identify mechanisms underlying $\mathrm{HCl}$-mediated apoptosis, the expression of MAPK proteins was examined by western blot analysis. After exposure to $\mathrm{HCl}$ ( $\mathrm{pH}$ 4.0 DMEM), the levels of phosphorylated JNK, p38 and ERK1/2 markedly increased in BEAS-2B cells compared with control BEAS-2B cells in 3 independent experiments, indicating that these three MAPK pathways were activated after $\mathrm{HCl}$ stimulation. Furthermore, after $\mathrm{HCl}$ exposure for 5, 15 and $30 \mathrm{~min}, \mathrm{JNK}, \mathrm{p} 38$ and ERK1/2 phosphorylation was found to be significantly increased in a time-dependent manner (Fig. 2). Based on these results and the literature, $\mathrm{pH}$ 4.0 DMEM was used to stimulate BEAS-2B cells for $30 \mathrm{~min}$.

HCl exposure induces cell injury and apoptosis. Cytotoxicity was observed when the cells were exposed to $\mathrm{HCl}$, which resulted in increased levels of $\mathrm{LDH}(\mathrm{P}<0.05$; Fig. $3 \mathrm{~B}) . \mathrm{HCl}$ exposure was also found to enhance the production of IL-8 $(\mathrm{P}<0.05)$, indicating that $\mathrm{HCl}$ induces cell injury and inflammation (Fig. 3C).

BEAS-2B cell apoptosis was determined by the assessment of cleaved caspase-3 (active form of caspase-3), fas and Bad expression by western blot analysis and the number of apoptotic cells using Annexin V/PI staining. Caspase-3, a key member of the caspase family, is widely accepted as a reliable indicator for cell apoptosis (15). Fas is an important molecule in the regulation of apoptosis (16). Bad is a pro-apoptotic protein in the Bcl-2 family (17). The upregulation of fas, caspase-3 and Bad constitutes the hallmark of cell apoptosis. In the present study, the levels of fas, caspase-3 and Bad were found to be significantly increased in the presence of $\mathrm{HCl}$. Furthermore, the number of positive cells following Annexin V/PI staining was significantly increased compared with the number of control cells (Fig. 4A).

Effects of MAPK inhibition on cell injury in BEAS-2B cells. To further investigate the association between MAPK activation and cell injury, BEAS-2B cells were pre-treated with JNK inhibitor II, SB202190 (p38 inhibitor) or U0126 (ERK1/2 inhibitor) in the presence of HCl. Pre-treatment with SB202190 and JNK inhibitor II reversed the decrease in BEAS-2B cell viability (Fig. 3A) and significantly inhibited the increase in LDH (Fig. 3B; P<0.05) and IL-8 expression (Fig. 3C; $\mathrm{P}<0.05$ ). However, pre-treatment with U0126 had no effect on cell viability, cytotoxicity or IL-8 production (Fig. 3A-C).

Effects of MAPK inhibition on BEAS-2B cell apoptosis. Pre-treatment with JNK inhibitor II or SB202190 decreased the levels of caspase-3, Bad and fas. However, pre-treatment with U0126 did not inhibit the expression of caspase-3, Bad or fas, suggesting that U0126 had no effect on cell apoptosis (Fig. 3D). These results indicate that $\mathrm{HCl}$ effectively induces apoptosis via the JNK and p38 pathways, as observed in the pre-treatment profiles of MAPK inhibitors.

\section{Discussion}

The present study demonstrated that: i) $\mathrm{HCl}$ exposure induces BEAS-2B cell injury and death; ii) the activation of JNK, p38 and ERK1/2 in BEAS-2B cells after $\mathrm{HCl}$ stimulation is time dependent; iii) the inhibition of JNK or p38 inhibits BEAS-2B cell injury and apoptosis and iv) the inhibition of ERK1/2 does not affect the level of IL-8, the release of LDH and the expression of apoptotic proteins. Furthermore, the JNK and p38 pathways were identified to be involved in $\mathrm{HCl}$-induced epithelial cell injury and death.

Acid-induced epithelial cell injury and death in vitro. Acid aspiration-induced lung injury is a common disease in the intensive care unit and is correlated with the prognosis of patients. The main characteristics of acid-induced ALI are increased permeability of the alveolar-capillary interface and alveolar as well as interstitial inflammation with edema. The intratracheal instillation of $\mathrm{HCl}$ is an in vivo model of ALI $(18,19)$. $\mathrm{HCl}$ has also been used to replicate the ALI model in vitro (9). The results of the present study indicated that the viability of BEAS-2B cells decreased and the number of dead cells increased with $\mathrm{HCl}$ treatment time. Furthermore, the release of IL- 8 and LDH was found to be increased in BEAS-2B cells after $\mathrm{HCl}$ exposure. These data showed that acid exposure induces epithelial cell injury and inflammation, and stimulates cell death.

Apoptosis, necrosis, and oncosis have been associated with cell death. Apoptosis has been suggested to be a mechanism underlying the pathogenesis of ALI/ARDS and other lung diseases $(20,21)$. Apoptosis is an active form of cell death, the timing of which is genetically determined during the course of development. Various biochemical features of apoptosis have been identified and are frequently used as an indication for apoptosis, such as caspase activation, DNA fragmentation and the externalization of phosphatidylserine, a cell surface marker for phagocytosis (22). Additional studies have demonstrated that alveolar epithelial injury in humans with ALI or ARDS is associated with the local upregulation of the Fas/FasL system and activation of the apoptotic cascade. The present study found that caspase-3, fas and Bad were increased after acid stimulation of BEAS-2B cells. Imai et al (23) demonstrated epithelial cell apoptosis in rabbit lungs after intratracheal administration of $\mathrm{HCl}$. Taken together, acid exposure in vivo and in vitro is suggested to induce epithelial cell apoptosis in ALI. Apoptosis is an important cellular mechanism in $\mathrm{HCl}$-induced cell injury. 

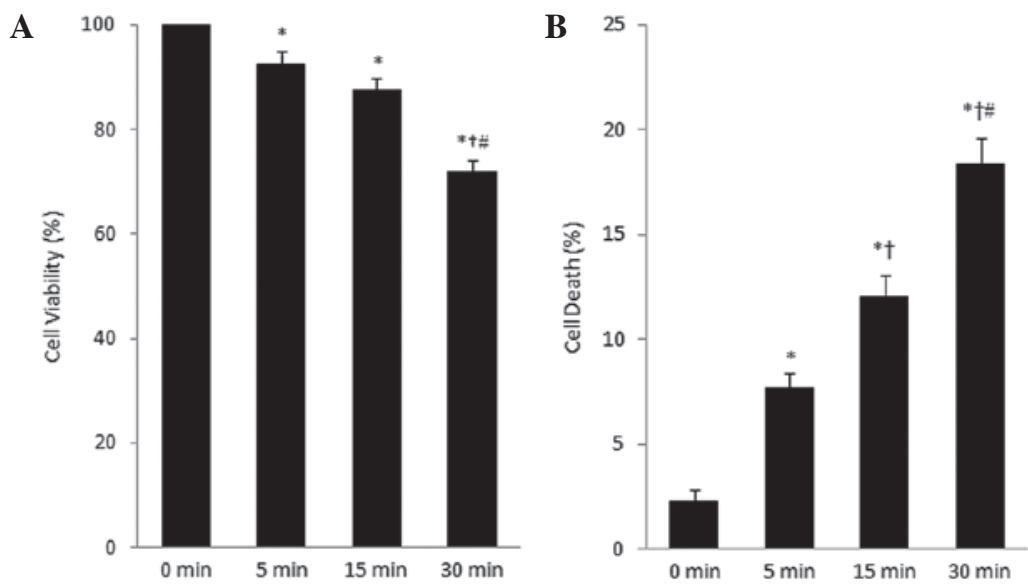

Figure 1. Effect of $\mathrm{HCl}$ on BEAS-2B cell viability and death. (A) A time-dependent effect of $\mathrm{HCl}$ treatment on BEAS-2B cell viability was observed. Cell viability was determined by MTT assay $4 \mathrm{~h}$ after $\mathrm{HCl}$ exposure for $0,5,15$ and $30 \mathrm{~min}$. (B) A time-dependent effect of $\mathrm{HCl}$ treatment on BEAS-2B cell death was observed. BEAS-2B cells were treated with $\mathrm{HCl}(\mathrm{pH} 4.0 \mathrm{DMEM})$ for $0,5,15$ and $30 \mathrm{~min}$. The cells were then cultured in DMEM for $4 \mathrm{~h}$. Cell death was determined by trypan blue staining $4 \mathrm{~h}$ after $\mathrm{HCl}$ exposure. Data are expressed as the means $\pm \mathrm{SEM}$; ${ }^{\mathrm{P}} \mathrm{P}<0.05 \mathrm{vs} .0 \mathrm{~min} ;{ }^{\dagger} \mathrm{P}<0.05 \mathrm{vs} .5 \mathrm{~min} ;{ }^{~} \mathrm{P}<0.05$ vs. $15 \mathrm{~min}$. $\mathrm{n}=9$ from three experiments. HCL, hydrochloric acid.
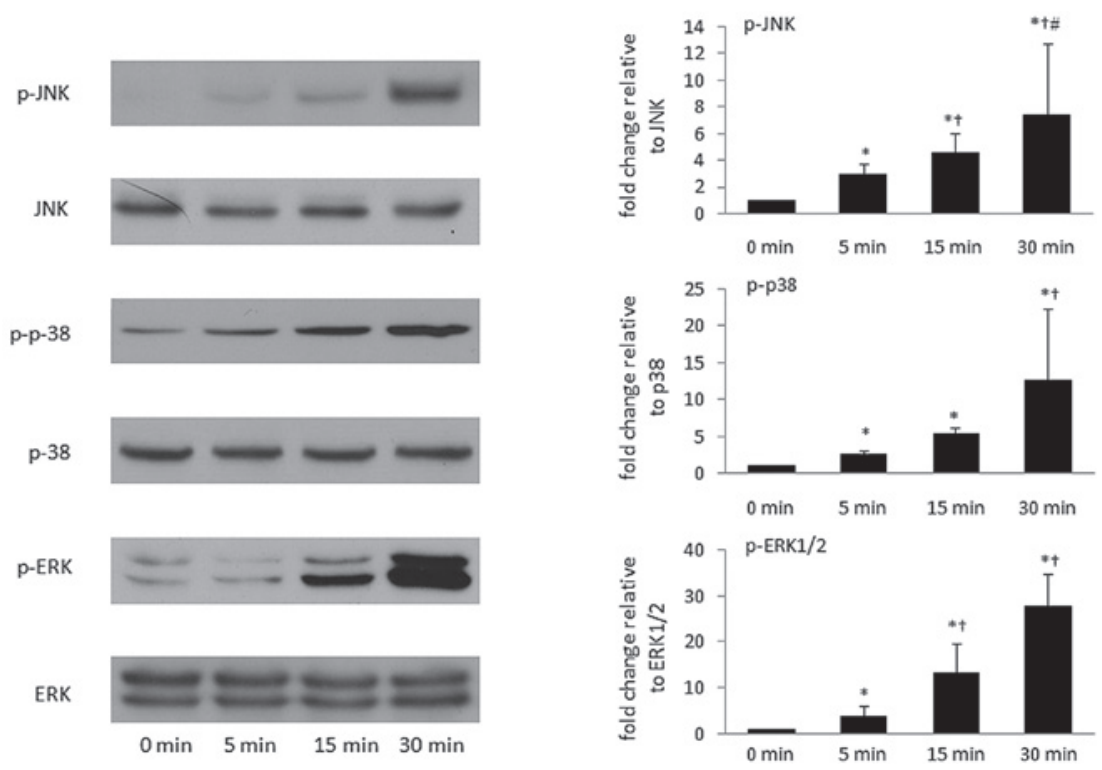

Figure 2. Effect of $\mathrm{HCl}$ on the activation of MAPKs in BEAS-2B cells. BEAS-2B cells were treated with $\mathrm{HCl}(\mathrm{pH} 4.0, \mathrm{DMEM})$ for $0,5,15$ and 30 min. The levels of MAPKs were determined by western blot analysis. For phosphorylated MAPKs, each protein level was normalized to the respective total MAPK level and is shown relative to the value for untreated control cells (normalized to 1). Data are expressed as the means \pm SEM; ${ }^{*} \mathrm{P}<0.05$ vs. 0 min; ${ }^{\dagger} \mathrm{P}<0.05$ vs. $5 \mathrm{~min}$; ${ }^{\#} \mathrm{P}<0.05$ vs. 15 min. $\mathrm{n}=9$ from three experiments. MAPKs, mitogen-activated protein kinases; HCL, hydrochloric acid.

Acid exposure activates MAPK family proteins in a time-dependent manner. The MAPK family consists of ERK, p38 MAPK and JNK. ERK is mainly activated by mitogenic stimuli, while p38 and JNK are mainly activated by stress stimuli or inflammatory cytokines (24). After acid exposure $(0.1 \mathrm{~N} \mathrm{HCl}$ for $3 \mathrm{~min})$, a rapid increase in the activity of ERK and $\mathrm{p} 38$ and a delayed increase in JNK activity were shown in the Barrett's adenocarcinoma cell line SEG-1 (25). The results of the present study showed that the phosphorylation of JNK, p38 and ERK1/2 was significantly increased in a time-dependent manner after acid administration. MAPKs are activated in LPS-induced ALI, and the inhibition of pulmonary MAPK activity abrogates LPS-induced inflammation and lung injury (26). $\mathrm{HCl}$ exposure induced epithelial cell apoptosis and activated the MAPK pathway. Coupled with the knowledge that MAPKs regulate cell proliferation and apoptosis, we hypothesize that the activation of the MAPK pathway plays a role in acid-induced epithelial cell apoptosis.

Effects of MAPK inhibitors on acid-induced epithelial cell injury and apoptosis. JNK has predominantly been positively associated with stress responses, including cytokine release and apoptosis (27). In the present study, the activation of JNK by $\mathrm{HCl}$ in BEAS-2B cells was associated with an increase in apoptotic protein levels. The inhibition of JNK by JNK inhibitor II decreased the concentration of apoptotic proteins. However, the reduction in apoptosis was only partial, suggesting that $\mathrm{HCl}$ may also induce apoptosis by pathways other than JNK. Alternatively, the JNK inhibitor II may not have inhibited JNK activity completely. In the present study, 
A

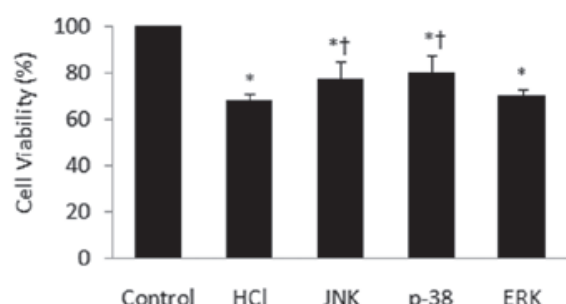

B

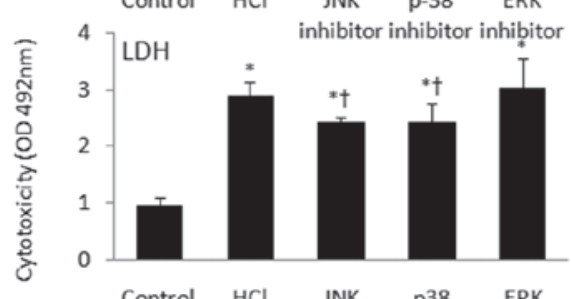

C

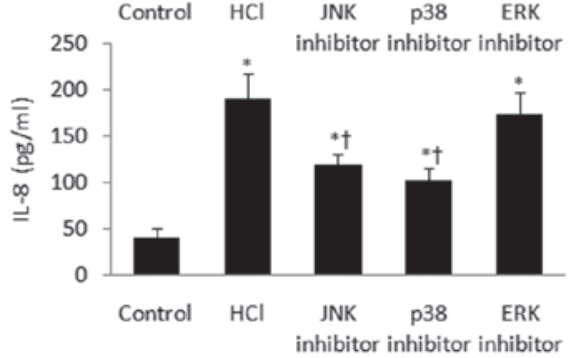

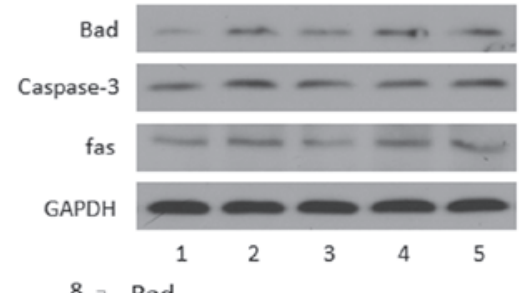
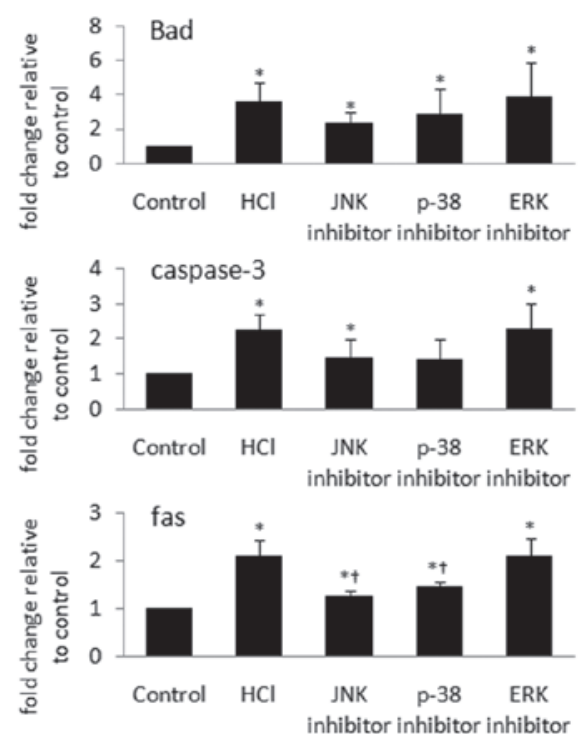

Figure 3. Effect of MAPK inhibitors on cell viability, cytotoxicity, IL-8 secretion and apoptosis in BEAS-2B cells exposed to HCl. BEAS-2B cells were pre-treated with MAPK inhibitors $(10 \mu \mathrm{M}) 30$ min prior to $\mathrm{HCl}$ exposure. (A) The effects of MAPK inhibitors on BEAS-2B cell viability were detected by MTT assay $4 \mathrm{~h}$ following $\mathrm{HCl}$ stimulation. (B) The effects of MAPK inhibitors on cytotoxicity were measured as the release of LDH from BEAS-2B cells in the supernatant $4 \mathrm{~h}$ following $\mathrm{HCl}$ exposure. (C) The effects of MAPK inhibitors on the expression of IL- 8 were detected by ELISA. The concentration of IL-8 in the supernatant was measured $4 \mathrm{~h}$ following $\mathrm{HCl}$ exposure. (D) Effects of MAPK inhibitors on cell apoptosis in BEAS-2B cells exposed to HCl. The levels of apoptotic proteins (Bad, caspase-3 and fas) were determined by western blot analysis. The protein levels were normalized to GAPDH and are shown relative to the value for untreated control cells (normalized to 1). 1, control; 2, $\mathrm{HCl} ; 3$, JNK inhibitor; 4, p38 inhibitor; 5, ERK inhibitor. Data are expressed as the means \pm SEM; ${ }^{*} \mathrm{P}<0.05$ vs. control; ${ }^{\circ} \mathrm{P}<0.05$ vs. $\mathrm{HCl}$. $\mathrm{n}=9$ from three experiments. MAPKs, mitogen-activated protein kinases; $\mathrm{LDH}$, lactate dehydrogenase; HCL, hydrochloric acid.

A
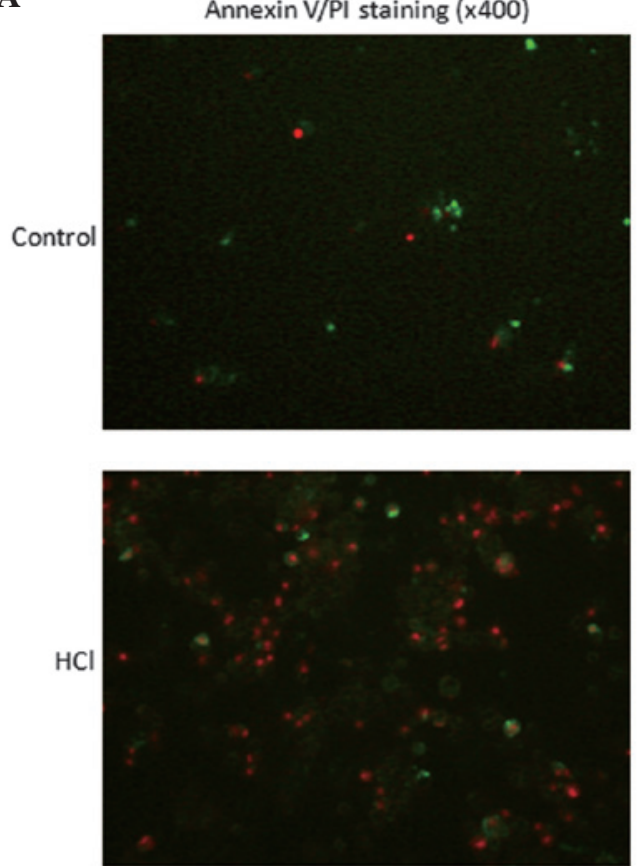

B
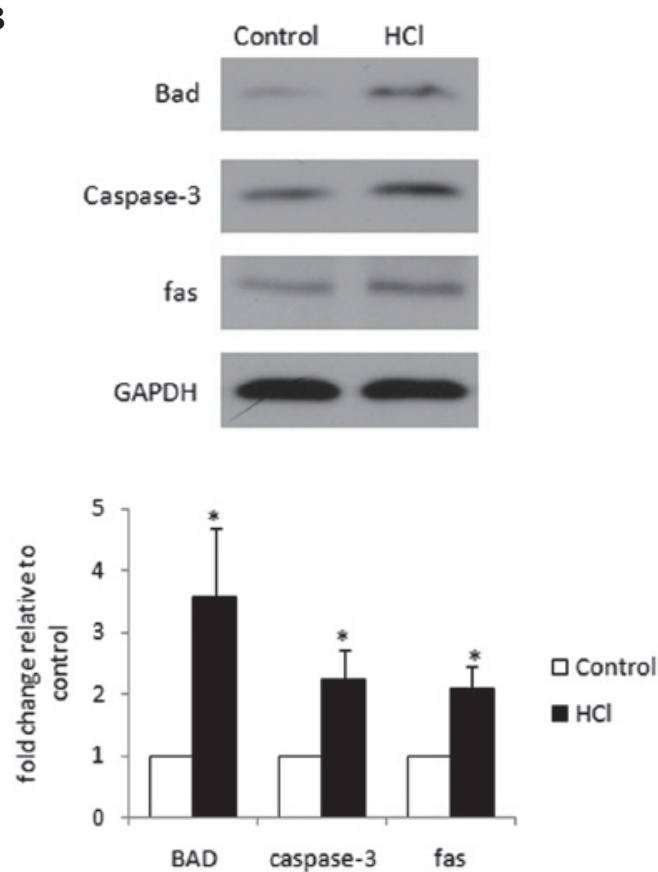

Figure 4. Effect of $\mathrm{HCl}$ exposure on BEAS-2B cell apoptosis. BEAS-2B cells were exposed to $\mathrm{HCl}$ (pH 4.0, DMEM) for 30 min. (A) Apoptosis of BEAS-2B cells was detected by Annexin V/PI staining (magnification, $x 400$ ). (B) Levels of the apoptotic proteins Bad, caspase-3 and fas were determined by western blot analysis. Each protein level was normalized to GAPDH and is shown relative to the value for untreated control cells (normalized to 1). Data are expressed as the means $\pm \mathrm{SEM} ;{ }^{*} \mathrm{P}<0.05$ vs. control cells. $\mathrm{n}=9$ from three experiments. HCL, hydrochloric acid. 
we also found that the inhibitor of p38, SB202190, decreased cell apoptosis. Thus, the p-38 MAPK pathway is suggested to be involved in $\mathrm{HCl}$-induced cell apoptosis.

Involvement of the ERK pathway in cell proliferation and apoptosis has previously been reported (28). In the present study, no change in the viability of BEAS-2B cells or the expression of apoptotic proteins was observed using ERK inhibitors. This result indicated that ERK activation in lung epithelial cells is not involved in the induction of apoptosis. Goillot et al (29) reported that ERK activation was transient and that JNK activation was sustained and correlated with the onset of apoptosis. This may partially explain why pre-treatment with U0126 in the present study did not affect cell viability or apoptosis after acid exposure.

In summary, acid exposure activates MAPKs in a time-dependent manner and induces lung epithelial cell injury and apoptosis in vitro. Moreover, the activation of p38 and $\mathrm{JNK}$ is involved in HCl-induced epithelial lung cell injury and apoptosis. Blockade of the JNK or p38 pathways is suggested to inhibit the apoptosis of BEAS-2B cells and reduce lung injury.

\section{Acknowledgements}

This study was supported by Projects of Jiangsu Province Medical Key Discipline (889-KJXW11.3), Health Research Special Funds for Public Welfare Projects (201202011) and a project of National Key Clinical Specialty Construction (2100299).

\section{References}

1. Villar J, Blanco J, Añón JM, et al: The ALIEN study: incidence and outcome of acute respiratory distress syndrome in the era of lung protective ventilation. Intensive Care Med 37: 1932-1941, 2011.

2. Phua J, Badia JR, Adhikari NK, et al: Has mortality from acute respiratory distress syndrome decreased over time? A systematic review. Am J Respir Crit Care Med 179: 220-227, 2009.

3. Miwa C, Koyama S, Watanabe Y, Tsubochi H, Endo S, Nokubi M and Kawabata Y: Pathological findings and pulmonary dysfunction after acute respiratory distress syndrome for 5 years. Intern Med 49: 1599-1604, 2010.

4. Segal BH, Davidson BA, Hutson AD, et al: Acid aspiration-induced lung inflammation and injury are exacerbated in NADPH oxidase-deficient mice. Am J Physiol Lung Cell Mol Physiol 292: L760-L768, 2007.

5. Reiss LK, Uhlig U and Uhlig S: Models and mechanisms of acute lung injury caused by direct insults. Eur J Cell Biol 91: 590-601,2012.

6. Marik PE: Aspiration pneumonitis and aspiration pneumonia. $\mathrm{N}$ Engl J Med 344: 665-671, 2001.

7. Fielhaber JA, Carroll SF, Dydensborg AB, et al: Inhibition of mammalian target of rapamycin augments lipopolysaccharide-induced lung injury and apoptosis. J Immunol 188: 4535-4542, 2012.

8. Fujita M, Kuwano K, Kunitake R, et al: Endothelial cell apoptosis in lipopolysaccharide-induced lung injury in mice. Int Arch Allergy Immunol 117: 202-208, 1998.

9. Ohwada A, Tsutsumi-Ishii Y, Yoshioka Y, Iwabuchi K, Nagaoka I and Fukuchi Y: Acid exposure potentiates intercellular adhesion molecule-1 and e-cadherin expression on A549 alveolar lining epithelial cells. Exp Lung Res 29: 389-400, 2003.
10. Kou B, Ni J, Vatish M and Singer DR: Xanthine oxidase interaction with vascular endothelial growth factor in human endothelial cell angiogenesis. Microcirculation 15: 251-267, 2008.

11. Vrana JA, Grant S and Dent P: Inhibition of the MAPK pathway abrogates BCL2-mediated survival of leukemia cells after exposure to low-dose ionizing radiation. Radiat Res 151: 559-569, 1999.

12. Mirzoeva OK, Das D, Heiser LM, et al: Basal subtype and MAPK/ERK kinase (MEK)-phosphoinositide 3-kinase feedback signaling determine susceptibility of breast cancer cells to MEK inhibition. Cancer Res 69: 565-572, 2009.

13. Cheng Y, Liu X, Zhang S, Lin Y, Yang J and Zhang C: MicroRNA-21 protects against the $\mathrm{H}_{2} \mathrm{O}_{2}$-induced injury on cardiac myocytes via its target gene PDCD4. J Mol Cell Cardiol 47: 5-14, 2009.

14. Tai KK, Blondelle SE, Ostresh JM, Houghten RA and Montal M: An N-methyl-D-aspartate receptor channel blocker with neuroprotective activity. Proc Natl Acad Sci USA 13: 3519-3524, 2001.

15. Kasof GM and Gomes BC: Livin, a novel inhibitor of apoptosis protein family member. J Biol Chem 276: 3238-3246, 2001.

16. Lopez AD, Avasarala S, Grewal S, Murali AK and London L: Differential role of the Fas/Fas ligand apoptotic pathway in inflammation and lung fibrosis associated with reovirus $1 / \mathrm{L}$-induced bronchiolitis obliterans organizing pneumonia and acute respiratory distress syndrome. J Immunol 183: 8244-8257, 2009.

17. Guo Q, Jin J, Yuan JX, Zeifman A, Chen J, Shen B and Huang J: VEGF, Bcl-2 and Bad regulated by angiopoietin-1 in oleic acid induced acute lung injury. Biochem Biophys Res Commun 413: 630-636, 2011.

18. Maniatis NA, Sfika A, Nikitopoulou I, et al: Acid-induced acute lung injury in mice is associated with p44/42 and c-Jun $\mathrm{N}$-Terminal kinase activation and requires the function of tumor necrosis factor $\alpha$ receptor I. Shock 38: 381-386, 2012.

19. Zimmermann AM, Roberts KD, Lampland AL, et al: Improved gas exchange and survival after KL-4 surfactant in newborn pigs with severe acute lung injury. Pediatr Pulmonol 45: 782-788, 2010.

20. Kim MN, Lee KE, Hong JY, Heo WI, Kim KW, Kim KE and Sohn MH: Involvement of the MAPK and PI3K pathways in chitinase 3-like 1-regulated hyperoxia-induced airway epithelial cell death. Biochem Biophys Res Commun 421: 790-796, 2012.

21. Roberson EC, Tully JE, Guala AS, et al: Influenza induces endoplasmic reticulum stress, caspase-12-dependent apoptosis, and c-Jun N-terminal kinase-mediated transforming growth factor- $\beta$ release in lung epithelial cells. Am J Respir Cell Mol Biol 46: 573-581, 2012.

22. Chopra M, Reuben JS and Sharma AC: Acute lung injury: apoptosis and signaling mechanisms. Exp Biol Med (Maywood) 234: 361-371, 2009.

23. Imai Y, Parodo J, Kajikawa O, et al: Injurious mechanical ventilation and end-organ epithelial cell apoptosis and organ dysfunction in an experimental model of acute respiratory distress syndrome. JAMA 289: 2104-2112, 2003.

24. Chang L and Karin M: Mammalian MAP kinase signalling cascades. Nature 410: 37-40, 2001.

25. Souza RF, Shewmake K, Terada LS and Spechler SJ: Acid exposure activates the mitogen-activated protein kinase pathways in Barrett's esophagus. Gastroenterology 122: 299-307, 2002.

26. Togbe D, Schnyder-Candrian S, Schnyder B, et al: Toll-like receptor and tumour necrosis factor dependent endotoxin-induced acute lung injury. Int J Exp Pathol 88: 387-391, 2007.

27. Verma G and Datta M: The critical role of JNK in the ER-mitochondrial crosstalk during apoptotic cell death. J Cell Physiol 227: 1791-1795, 2012.

28. Park H, Im JY, Kim J, Choi WS and Kim HS: Effects of apicidin, a histone deacetylase inhibitor, on the regulation of apoptosis in H-ras-transformed breast epithelial cells. Int J Mol Med 21: 325-333, 2008

29. Goillot E, Raingeaud J, Ranger A, Tepper RI, Davis RJ, Harlow E and Sanchez I: Mitogen-activated protein kinase-mediated Fas apoptotic signaling pathway. Proc Natl Acad Sci USA 94: 3302-3307, 1997. 